\title{
Synthesis of New Polyguanamine Macromonomers by Self-Polyaddition and Their Copolymerization
}

\author{
Hideo Kunisada, Yasuo Yuki, Shuji Kondo, Yoshiki Nishimori, \\ and Akitoshi MaSUYAMA \\ Department of Materials Science and Engineering, Nagoya Institute of Technology, \\ Gokiso-cho, Showa-ku, Nagoya 466, Japan
}

(Received May 7, 1991)

\begin{abstract}
Polyguanamine macromonomers were synthesized by self-polyaddition reaction of 2-amino-4-( $m$-amino- $N$-alkylanilino)-6-isopropenyl-1,3,5-triazines. Alkyl groups were ethyl and octadecyl. Molecular weight of the macromonomers was determined to be $3000-4000$ (number average molecular weight) by their ${ }^{1} \mathrm{H}$ NMR spectra and gel permeation chromatography. Copolymerizations of the macromonomers with styrene and methyl methacrylate were carried out to give the graft copolymer. Glass transition temperature $\left(T_{\mathrm{g}}\right)$ and decomposition temperature were determined by thermal analysis. Only a single $T_{\mathrm{g}}$ was observed for the resulting graft copolymers. The thermal properties of the graft copolymers were compared with those of random copolymers.

KEY WORDS Isopropenyltriazines / Polyguanamines / Self-Polyaddition / Macromonomer / Graft Copolymer / Glass Transition Temperature /
\end{abstract}

The macromonomer technique is the most useful method to prepare graft copolymer having branches with welldefined length. ${ }^{1}$ Michael type self-polyaddition for monomers containing both vinyl group activated by electron withdrawing group and nucleophilic group is expected to form the macromonomer with one polymerizable functional group as an end group.
Oda et al. found that a vinyl group attached directly to triazine ring reacted with nucleophilic reagents such as amines and thiols. ${ }^{2}$ By application of this reaction, we reported previously the synthesis of polyguanamine by self-polyaddition of 2-amino-4-( $\mathrm{m}$-aminoanilino)-6-isopropenyl-1,3,5-triazine. ${ }^{3}$ The resulting polymer exhibited excellent thermal stability. However, copolymerization of the<smiles>[Y14]C(C)CC(C)(C)c1nc(N)nc(N([R])c2cccc(NC(C)(C)CC)c2)n1</smiles>

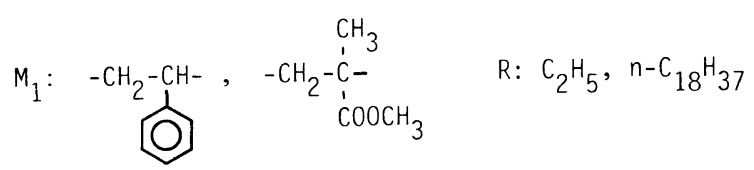

Scheme 1. 
macromonomer could not be carried out because of poor solubility. The introduction of alkyl group into the monomer unit would be expected to improve the solubility of the macromonomer. Graft copolymers obtained from the copolymerization of the resulting macromonomers with conventional comonomers can be expected for good thermal stability. In addition, the copolymerization of the macromonomer containing long alkyl group gives specific structural polymer which has long alkyl side-chains in the branches (comb-like branch) of the graft copolymer.

This paper describes the preparation of 2amino-4-( $m$-amino- $N$-alkylanilino)-6-isopropenyl-1,3,5-triazines whose alkyl groups are ethyl and octadecyl, and the self-polyaddition of these monomers to produce polyguanamine macromonomers. Further, characterization of graft copolymers obtained by the copolymerization of the resulting macromonomers with styrene or methyl methacrylate is presented. The structure of the graft copolymers synthesized in this study is shown in Scheme 1.

\section{EXPERIMENTAL}

\section{Materials and Instruments}

The starting material, 2-amino-4-( $m$-nitroanilino)-6-isopropenyl-1,3,5-triazine (ANIT) was prepared by the reaction of $1-(m$-nitrophenyl)biguanide with methacryloyl chloride as described in the previous paper. ${ }^{4}$ Styrene (St) and methyl methacrylate (MMA) were purified by usual procedures. Benzene, $N, N$ dimethylformamide (DMF), N,N-dimethylacetamide (DMAc), and dimethyl sulfoxide
(DMSO) were dried and purified by distillation. Other reagents were obtained commercially and used without further purification.

${ }^{1} \mathrm{H}$ NMR spectrum was obtained with a Varian XL-200 $(200 \mathrm{MHz})$. Gel permeation chromatography (GPC) was carried out on a TOSOH HLC-803D with G2000, G3000, and GMH TSK gel-columns and a differential refractometric detector in tetrahydrofuran (THF). The columns were calibrated with a set of monodisperse polystyrene standards. Melting temperatures $(\mathrm{mp})$ and glass transition temperatures $\left(T_{\mathrm{g}}\right)$ of polymers were determined by differential scanning calorimetry (DSC) on a Rigaku-Denki DSC-8230 at a heating rate of $20^{\circ} \mathrm{C} \mathrm{min}^{-1}$. DSC at low temperature region was measured from $-120^{\circ} \mathrm{C}$ to $150^{\circ} \mathrm{C}$ on a Rigaku-Denki Thermoflex with a low temperature unit (Rigaku-Denki DSC-8131BL) at the heating and cooling rates $10^{\circ} \mathrm{Cmin}^{-1}$. Thermal stability of the polymers was examined by thermogravimetry (TG)-differential thermal analysis (DTA) on a Rigaku-Denki TG-DTA-81 10 at a heating rate of $10^{\circ} \mathrm{C} \mathrm{min}^{-1}$ in an atmosphere of air.

\section{Monomers}

The monomers used in this study were synthesized according to Scheme 2.

2-Amino-4-( $m$-amino- $N$-ethylanilino)-6isopropenyl-1,3,5-triazine (AN2). At first, 2amino-4-( $m$-nitro- $N$-ethylanilino)-6-isopropenyl-1,3,5-triazine (NN2) was prepared by the alkylation of ANIT ( $54.8 \mathrm{~g}, 0.2 \mathrm{mmol})$ with ethyl iodide $(31.2 \mathrm{~g}, 0.2 \mathrm{~mol})$ in the presence of potassium hydroxide $(14.0 \mathrm{~g}, 0.25 \mathrm{~mol})$ in DMF $(600 \mathrm{ml})$ at $30^{\circ} \mathrm{C}$ for $20 \mathrm{~h}$. The reaction

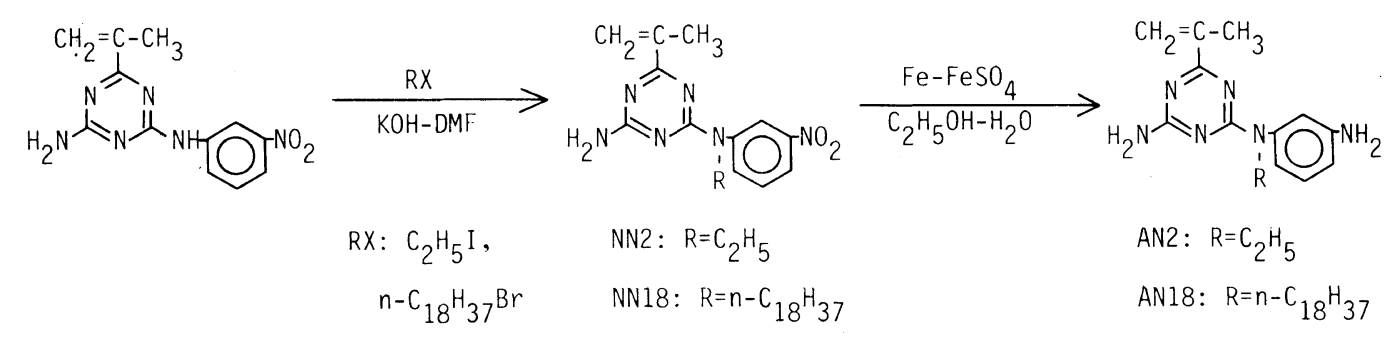

Scheme 2. 
mixture was poured into a large excess of water to precipitate the solid. The crude product was recrystallized from methanol: yield $48.4 \mathrm{~g}(81 \%), \mathrm{mp} 119^{\circ} \mathrm{C}$. Elemental analysis. Calcd for $\mathrm{C}_{14} \mathrm{H}_{16} \mathrm{~N}_{6} \mathrm{O}_{2}$ : C, 55.99\%; $\mathrm{H}, 5.37 \%$; N, 27.98\%. Found: C, 55.80\%; H, $5.63 \% ; \mathrm{N}, 27.92 \%$.

AN2 was prepared by reduction of NN2. NN2 $(40.0 \mathrm{~g}, 0.13 \mathrm{~mol})$ was added to mixture of ethanol $(500 \mathrm{ml})$ and water $(150 \mathrm{ml})$ in the presence of iron powder $(100 \mathrm{~g})$ and iron(II) sulfate heptahydrate $(40.7 \mathrm{~g}, 0.15 \mathrm{~mol})$, and the mixture was refluxed with stirring for $5 \mathrm{~h}$. After filtration of the reaction mixture, the filtrate was poured into a large excess of water to precipitate the solid. The crude product was purified by reprecipitation from methanol into water: yield $19.4 \mathrm{~g}(54 \%), \mathrm{mp} 130^{\circ} \mathrm{C}$. Elemental analysis. Calcd for $\mathrm{C}_{14} \mathrm{H}_{18} \mathrm{~N}_{6}$ : C, $62.20 \% ; \mathrm{H}, 6.71 \% ; \mathrm{N}, 31.09 \%$. Found: C, $62.45 \%$; H, 6.75\%; N, 31.13\%. ${ }^{1} \mathrm{H}$ NMR (DMSO- $\left.d_{6}\right), \delta 1.14\left(\mathrm{t}, 3 \mathrm{H}, \mathrm{CH}_{3}\right), 2.00(\mathrm{~s}, 3 \mathrm{H}$, $\mathrm{CH}_{3}$ ), 3.90 (q, 2H, $\mathrm{CH}_{2}$ ), $5.27\left(\mathrm{~s}, 2 \mathrm{H}, \mathrm{NH}_{2}\right.$ ), $5.43(\mathrm{~s}, 1 \mathrm{H},=\mathrm{CH}), 6.26(\mathrm{~s}, 1 \mathrm{H},=\mathrm{CH}), 6.79$ $\left(\mathrm{s}, 2 \mathrm{H}, \mathrm{NH}_{2}\right), 6.38-7.14 \mathrm{ppm}\left(\mathrm{m}, 4 \mathrm{H}, \mathrm{C}_{6} \mathrm{H}_{4}\right)$.

2-Amino-4-( $m$-amino- $N$-octadecylanilino)6-isopropenyl-1,3,5-triazine (AN18). 2-Amino4-( $m$-nitro- $N$-octadecylanilino)-6-isopropenyl1,3,5-triazine (NN18) was prepared by the reaction of ANIT with octadecyl bromide similarly to the preparation of NN2. The crude product was recrystallized twice from methanol: yield $82 \%, \mathrm{mp} 83^{\circ} \mathrm{C}$. Elemental analysis. Calcd for $\mathrm{C}_{30} \mathrm{H}_{48} \mathrm{~N}_{6} \mathrm{O}_{2}: \mathrm{C}, 68.67 \%$; H, 9.22\%; N, $16.02 \%$. Found: C, $68.67 \%$; H, $9.26 \% ; \mathrm{N}, 15.85 \%$.

AN18 was prepared by reduction of NN18 similarly to the preparation of AN2. The crude product was recrystallized from $n$-hexane, and further recrystallized from methanol: yield $62 \%, \mathrm{mp} 86^{\circ} \mathrm{C}$. Elemental analysis. Calcd for $\mathrm{C}_{30} \mathrm{H}_{50} \mathrm{~N}_{6}: \mathrm{C}, 72.83 \% ; \mathrm{H}, 10.19 \% ; \mathrm{N}$, $16.99 \%$. Found: C, $72.85 \%$; H, $10.30 \%$; , $16.93 \% .{ }^{1} \mathrm{H}$ NMR $\left(\mathrm{CDCl}_{3}\right), \delta 0.88(\mathrm{t}, 3 \mathrm{H}$, $\left.\mathrm{CH}_{3}\right), 1.26\left(\mathrm{~m}, 30 \mathrm{H}, \mathrm{C}_{15} \mathrm{H}_{30}\right), 1.61(\mathrm{~m}, 2 \mathrm{H}$, $\left.\mathrm{CH}_{2}\right), 2.09$ (s, 3H, $\left.\mathrm{CH}_{3}\right), 3.82\left(\mathrm{~s}, 2 \mathrm{H}, \mathrm{NH}_{2}\right)$, $3.89\left(\mathrm{t}, 2 \mathrm{H}, \mathrm{CH}_{2}\right), 5.44$ (brs, $3 \mathrm{H}, \mathrm{NH}_{2}$ and $=\mathrm{CH}), 6.34(\mathrm{~s}, 1 \mathrm{H},=\mathrm{CH}), 6.46-7.22 \mathrm{ppm}$ $\left(\mathrm{m}, 4 \mathrm{H}, \mathrm{C}_{6} \mathrm{H}_{4}\right.$ ).

\section{Synthesis of Macromonomers; APAN2 and APAN18}

Self-polyaddition of AN2 or AN18 was carried out at $120^{\circ} \mathrm{C}$ in DMAc. After the polymerization, the reaction mixture was poured into methanol-water $(4: 1, \mathrm{v} / \mathrm{v})$ to precipitate the solid. The resulting macromonomer was purified by reprecipitation from THF into benzene in the case of self-polyaddition of AN2, and from THF into methanol-water $(10: 1, v / v)$ in the case of that of AN18. Molecular weight of the resulting macromonomers was determined by GPC. That was also estimated from peak intensity ratio of methyl proton of isopropenyl group in endgroup and phenyl proton ( $m$-position toward both amino groups, $7.06 \mathrm{ppm}$ ) in the ${ }^{1} \mathrm{H}$ NMR spectra.

\section{Copolymerization}

The copolymerizations of the macromonomers with St and MMA were carried out using 2,2-azobisisobutyronitrile (AIBN) as an initiator in benzene or DMAc at $60^{\circ} \mathrm{C}$. The required volumes of monomers and AIBN solutions were charged into polymerization tubes and sealed under vacuum. The tubes were placed in a constant temperature bath for specified times. The polymerization mixture was poured into a large excess of methanol. The precipitated polymer was purified by repeated reprecipitations from THF into methanol in the case of copolymerizations of macromonomers from AN2, and from benzene into $n$-hexane in the case of those from AN18. The copolymerizations of AN2 and AN18 with St and MMA were carried out in a similar manner to the copolymerization of the macromonomers. The compositions of the copolymers were calculated by elemental analysis of carbon and nitrogen content. 
H. KunisADa et al.

Table I. Homopolymerization of AN2 and AN18

\begin{tabular}{|c|c|c|c|c|c|c|c|}
\hline \multirow{2}{*}{ Monomer } & Time & Yield & $\eta_{\mathrm{sp}} / c^{\mathrm{b}}$ & $\bar{M}_{w}^{\mathrm{c}}$ & $\bar{M}_{n}^{\mathrm{c}}$ & $T_{\mathrm{g}}^{\mathrm{d}}$ & $T_{\mathrm{d}}^{\mathrm{e}}$ \\
\hline & $\mathrm{h}$ & $\%$ & $\mathrm{dlg}^{-1}$ & $\times 10^{-3}$ & $\times 10^{-3}$ & ${ }^{\circ} \mathrm{C}$ & ${ }^{\circ} \mathrm{C}$ \\
\hline AN2 & 7 & 33 & 0.30 & 3.5 & 1.6 & 224 & 365 \\
\hline AN18 & 50 & 8 & 0.12 & 3.3 & 2.0 & 163 & 370 \\
\hline
\end{tabular}

a Polymerization conditions: $[\mathrm{M}]_{0}=0.4 \mathrm{~mol}^{-1}$, $[\mathrm{AIBN}]=1.5 \mathrm{mmol}^{-1}$ at $60^{\circ} \mathrm{C}$ in DMAc.

b $c=0.2 \mathrm{~g} \mathrm{dl}^{-1}$ at $30^{\circ} \mathrm{C}$ in DMSO for poly(AN2), in THF for poly(AN18).

c Determined by GPC.

d Measured by DSC at a heating rate of $20^{\circ} \mathrm{C} \mathrm{min}^{-1}$.

e $5 \%$ Weight loss temperature observed by TG.

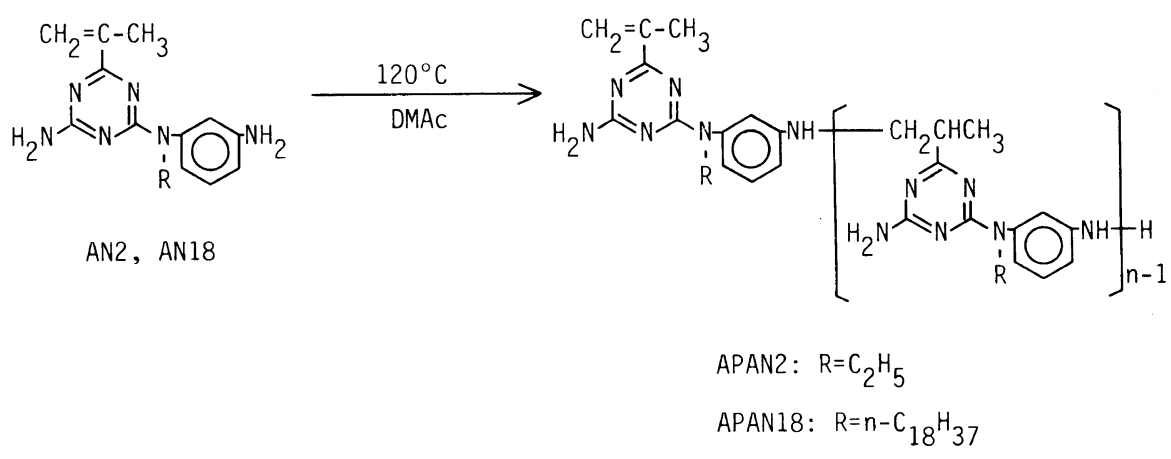

Scheme 3.

\section{RESULTS AND DISCUSSION}

\section{Preparation of Monomers}

AN2 and AN18 were prepared from ANIT as shown in Scheme 2. The alkylation of ANIT took place selectively toward the nitrogen atom of anilino group. The reduction of nitro group in NN2 and NN18 could be achieved without side reactions by use of iron and iron(II) sulfate as the reducing agent. Structure of the monomers was confirmed by ${ }^{1} \mathrm{H}$ NMR, IR, and elemental analysis.

\section{Vinyl Polymerization of AN2 and AN18}

Homopolymerization of AN2 and AN18 and their copolymerization with St and MMA were carried out using AIBN as an initiator in DMAc at $60^{\circ} \mathrm{C}$. The results of the homopolymerization are shown in Table I. The molecular weight of the both polymers was lower than that of poly(2-amino-4- $(\mathrm{N}$-alkyl-
Table II. Monomer reactivity ratios

\begin{tabular}{clcc}
\hline $\mathrm{M}_{2}$ & $\mathrm{M}_{1}$ & $r_{1}$ & $r_{2}$ \\
\hline \multirow{2}{*}{$\mathrm{AN} 2$} & $\mathrm{St}$ & $0.55 \pm 0.18$ & $0.79 \pm 0.19$ \\
& MMA & $0.60+0.15$ & $0.54 \pm 0.12$ \\
AN18 & St & $0.32 \pm 0.06$ & $0.39 \pm 0.28$ \\
& MMA & $0.46 \pm 0.04$ & $0.25 \pm 0.08$ \\
\hline
\end{tabular}

anilino)-6-isopropenyl-1,3,5-triazine)s. ${ }^{5}$ This would be due to the chain transfer of propagating radical to amino group on benzene ring. The polymerization yield of AN18 was lower than that of AN2. Because the solubility of the polymer containing long alkyl groups is similar to that of the monomer, the low yield would owe to loss of oligomer, which is evolved by chain transfer, in the isolation of the polymer by reprecipitation. The resulting polymers showed relatively high $T_{\mathrm{g}}$ and decomposition temperature $\left(T_{\mathrm{d}}\right)$ in vinyl polymers. 
Table III. Self-polyaddition of AN2 and AN18

\begin{tabular}{|c|c|c|c|c|c|c|c|c|c|c|c|c|c|c|c|}
\hline \multirow{3}{*}{ Run } & \multirow{3}{*}{ Polymer } & \multicolumn{5}{|c|}{ Polymerization condition ${ }^{\mathrm{a}}$} & \multirow{3}{*}{$\frac{\text { Yield }}{\%}$} & \multirow{3}{*}{$\frac{\eta_{\mathrm{sp}} / c^{\mathrm{c}}}{\mathrm{dlg}^{-1}}$} & \multicolumn{3}{|c|}{ GPC } & \multicolumn{2}{|c|}{ NMR } & \multirow{2}{*}{$T_{\mathrm{g}}^{\mathrm{e}}$} & \multirow{2}{*}{$T_{\mathrm{d}}^{\mathrm{f}}$} \\
\hline & & \multirow{2}{*}{ Monomer } & \multirow{2}{*}{$\frac{\text { Feed }}{\mathrm{g}}$} & \multirow{2}{*}{$\frac{\text { DMAc }}{\mathrm{ml}}$} & \multirow{2}{*}{ Cat. $^{b}$} & \multirow{2}{*}{$\frac{\text { Time }}{\mathrm{h}}$} & & & \multirow{2}{*}{$\frac{\bar{M}_{w}}{\times 10^{-3}}$} & \multirow{2}{*}{$\frac{\bar{M}_{n}}{\times 10^{-3}}$} & \multirow{2}{*}{$\bar{n}$} & $\bar{M}_{n}$ & \multirow{2}{*}{$-\bar{n}$} & & \\
\hline & & & & & & & & & & & & $\times 10^{-3}$ & & ${ }^{\circ} \mathrm{C}$ & ${ }^{\circ} \mathrm{C}$ \\
\hline 1 & APAN2 & AN2 & 1.0 & 3 & $\mathrm{Cu}\left(\mathrm{CH}_{3} \mathrm{COO}\right)_{2}$ & 300 & 46 & 0.10 & 2.7 & 2.0 & 7.4 & & & & \\
\hline 2 & & & 1.0 & 3 & $\mathrm{LiCl}$ & 330 & 33 & 0.10 & 3.4 & 2.4 & 8.9 & & & & \\
\hline 3 & & & 1.0 & 3 & - & 330 & 35 & 0.09 & 2.8 & 2.2 & 8.1 & 2.4 & 8.9 & & \\
\hline 4 & & & 14.9 & 15 & - & 320 & 96 & 0.30 & 4.5 & 3.3 & 12.2 & 3.4 & 12.4 & 114 & 347 \\
\hline 5 & APAN18 & AN18 & 1.0 & 3 & $\mathrm{Cu}\left(\mathrm{CH}_{3} \mathrm{COO}\right)_{2}$ & 320 & 48 & 0.19 & 3.7 & 2.0 & 4.0 & & & & \\
\hline 6 & & & 1.0 & 3 & $\mathrm{LiCl}$ & 320 & 67 & 0.21 & 4.6 & 3.0 & 6.0 & & & & \\
\hline 7 & & & 1.0 & 3 & - & 330 & 72 & 0.20 & 4.2 & 3.1 & 6.3 & & & & \\
\hline 8 & & & 5.4 & 4 & - & 240 & 95 & 0.30 & 6.1 & 4.2 & 8.5 & 3.7 & 7.4 & 52 & 377 \\
\hline
\end{tabular}


In the copolymerizations of AN2 and AN18 with St and MMA, yields of the copolymers were kept below $15 \%$. Copolymer composition was calculated from carbon-nitrogen ratio in the elemental analysis. The monomer reactivity ratios $r_{1}$ and $r_{2}$, determined by the Kelen-Tüdös method, ${ }^{6}$ are shown in Table II. The values indicated that random copolymers could be obtained by copolymerization.

\section{Synthesis of Macromonomers}

In order to synthesis the polyguanamine macromonomers, self-polyaddition reaction of AN2 and AN18 was carried out in DMAc at $120^{\circ} \mathrm{C}$ (Scheme 3). Oda et al. reported that copper(II) acetate was efficient catalyst for the addition reaction of 2,4-diamino-6-vinyl-1,3,5triazine with nucleophilic reagents such as amines and thiols. ${ }^{2}$ In addition, lithium chloride is known to be effective for the Michael type polyaddition of $N, N$-dimethacryloylhydrazine with dithiols. ${ }^{7}$ Therefore, the self-polyaddition was examined by use of copper(II) acetate or lithium chloride as the catalyst according to the previous papers. The results of the self-polyaddition are summarized in Table III. Significant effects of the catalysts on the yield and molecular weight of the polyguanamine macromonomers were not observed. Both yield and molecular weight increased by increase in monomer concentration (runs 4 and 8 in Table III). Crosslinked polymer (insoluble polymer), which would be derived by simultaneous occurrence of vinyl polymerization with the self-polyaddition, was not obtained. The possibility of vinyl polymerization during the self-polyaddition was examined by reaction of 2-amino-4-( $N$-ethylanilino)-6-isopropenyl-1,3,5-triazine (N2) or 2amino-4-( $N$-octadecylanilino)-6-isopropenyl1,3,5-triazine (N18) under the same conditions as the self-polyaddition of AN2 and AN18. Both reactions did not produce the polymer, and only unchanged $\mathrm{N} 2$ and N18 was recovered. This result indicates that the vinyl polymerization does not proceed simultan- eously with self-polyaddition under the present condition. This would be due to the low ceiling temperature of isopropenyltriazines. We reported in the previous papers that the ceiling temperatures in bulk were $163^{\circ} \mathrm{C}$ for $\mathrm{N} 2{ }^{8}$ and below $130^{\circ} \mathrm{C}$ for $\mathrm{N} 18,{ }^{9}$ respectively. The ceiling temperature at the monomer concentration of the present self-polyaddition would be below $120^{\circ} \mathrm{C}$. The above result also indicates that amino group directly attached to triazine ring (2-position) does not participate in the self-polyaddition. This is attributed to the weak nucleophilicity of the amino group caused by the electron-attracting character of the triazine ring.

The ${ }^{1} \mathrm{H}$ NMR spectra of the polyguanamine macromonomers are shown in Figure 1, together with those for monomers. Signals of methylene and methyne protons in polymer main-chain are observed at 3.1 and $2.8 \mathrm{ppm}$, respectively. The signal of the imino proton is also observed at $5.8 \mathrm{ppm}$ for APAN2 and at $4.6 \mathrm{ppm}$ for APAN18. In addition, small signals based on the terminal isopropenyl

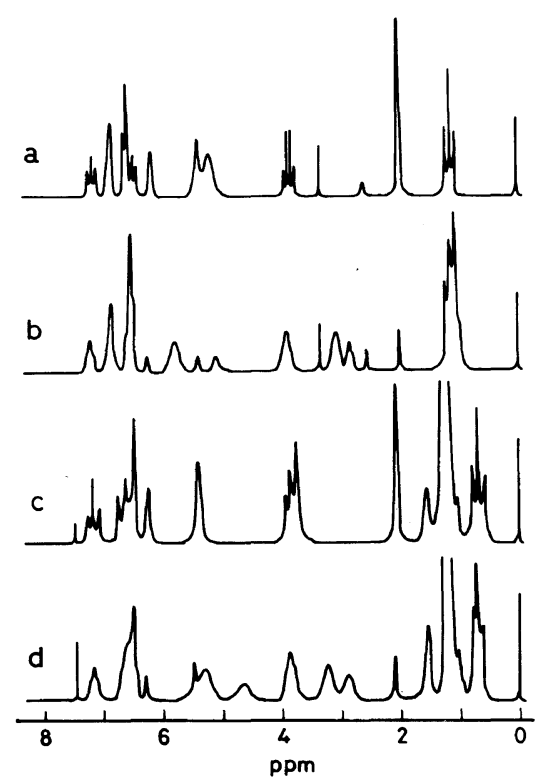

Figure 1. ${ }^{1} \mathrm{H}$ NMR spectra of (a) AN2 in DMSO- $d_{6}$, (b) APAN2 in DMSO- $d_{6}$, (c) AN18 in $\mathrm{CDCl}_{3}$, and (d) APAN18 in $\mathrm{CDCl}_{3}$. 
group can be detected at $2.0 \mathrm{ppm}, 5.4 \mathrm{ppm}$, and $6.3 \mathrm{ppm}$. Molecular weight of the macromonomers was calculated from the integral ratio of the methyl protons of the isopropenyl group ( $\delta 2.0 \mathrm{ppm})$ to one of the phenyl protons $(\delta 7.2 \mathrm{ppm})$ in the ${ }^{1} \mathrm{H}$ NMR spectra, and was shown in Table III. The resulting molecular weights are close to the values determined by GPC.

The solubility of resulting polyguanamine macromonomes was good in contrast to that of polyguanamine prepared by self-polyaddition of 2-amino-4-( $m$-aminoanilino)-6-isopropenyl-1,3,5-triazine. ${ }^{3}$ APAN2 was soluble in THF, chloroform, 1,4-dioxane, pyridine, and polar aprotic solvents such as $N$-methyl2-pyrrolidone, DMF, DMAc, and DMSO. APAN18 was soluble in these solvents and in benzene, toluene, and diethyl ether. It was revealed that the introduction of alkyl groups into the polyguanamine backbone resulted in a improvement of solubility.

\section{Synthesis of Graft Copolymers}

In the homopolymerizations of APAN2 and APAN18, the homopolymer could not be obtained and the macromonomers were recovered. This would be due to the low ceiling temperature of the macromonomers. The macromonomers $\left(\mathbf{M}_{2}\right)$ could be copolymerized with $\mathrm{St}$ and MMA $\left(\mathrm{M}_{1}\right)$. Figure 2 shows typical GPC curves for graft copolymer obtained by the copolymerization of APAN2 with St together with that for APAN2. The GPC curve of the copolymerization product precipitated into methanol shows two peaks based on the macromonomer and graft copolymer (Figure 2, b). The graft copolymer could be isolated by repeated reprecipitations as shown in Figure 2, c. The other graft copolymers could be also isolated by the reprecipitations.

Results of the copolymerizations are summarized in Table IV. The rates of the copolymerizations with St were lower than those with MMA. This would be due to low
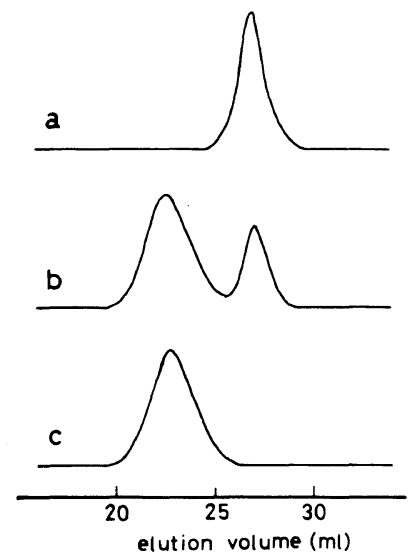

Figure 2. GPC curves of (a) APAN2 $\left(\bar{M}_{n}=3300\right)$, (b) precipitate obtained from a solution of copolymerization of APAN2 with St into methanol (run 1 in Table IV), and (c) graft copolymer purified twice by reprecipitations from THF into methanol $\left(\bar{M}_{n}=22400\right)$.

propagation rate constant in homopolymerization of St compared with that of MMA, because the copolymerizations were carried out at high fraction of $\mathrm{M}_{1}$ (St or MMA) feed. ${ }^{20}$ The macromonomer $\left(\mathbf{M}_{2}\right)$ content in the graft copolymer $\left(\mathrm{dm}_{2}\right)$ was calculated from carbon-nitrogen ratio in the elemental analysis. Under the limiting conditions of $\left[\mathrm{M}_{1}\right] /\left[\mathrm{M}_{2}\right] \gg 1$, Mayo-Lewis copolymerization equation (eq 1$)^{10}$ can be reduced to equation $2 .^{11,12}$

$$
\begin{gathered}
\frac{\mathrm{d}\left[\mathrm{M}_{1}\right]}{\mathrm{d}\left[\mathrm{M}_{2}\right]}=\frac{1+r_{1}\left[\mathrm{M}_{1}\right] /\left[\mathrm{M}_{2}\right]}{1+r_{2}\left[\mathrm{M}_{2}\right] /\left[\mathrm{M}_{1}\right]} \\
\frac{\mathrm{d}\left[\mathrm{M}_{1}\right]}{\mathrm{d}\left[\mathrm{M}_{2}\right]}=r_{1} \frac{\left[\mathrm{M}_{1}\right]}{\left[\mathrm{M}_{2}\right]}
\end{gathered}
$$

The monomer reactivity ratio $r_{1}$ was calculated from equation 2, and is shown in Table IV. $r_{1}$ for the copolymerizations of APAN2 with St and MMA were close to those for the copolymerizations of AN2 with St and MMA (Table II). It has been reported that the relative reactivity $\left(1 / r_{1}\right)$ of the terminal double bond of several macromonomers decreases when the molecular weight of the macromonomers is high. ${ }^{12-15}$ Our results might be due to the low 
H. KUNISADA et al.

Table IV. Copolymerization of polyguanamine macromonomers ${ }^{\mathrm{a}}$

\begin{tabular}{|c|c|c|c|c|c|c|c|c|c|c|c|}
\hline \multirow{2}{*}{ Run } & \multirow{2}{*}{$\mathrm{M}_{2}$} & \multirow{2}{*}{$\mathrm{M}_{1}$} & \multirow{2}{*}{$\frac{\left[\mathrm{M}_{2}\right]}{\mathrm{mol} \%}$} & \multirow{2}{*}{$\frac{\text { Time }}{h}$} & \multirow{2}{*}{$\frac{\text { Yield }}{\%}$} & \multirow{2}{*}{$\frac{\mathrm{dm}_{2}}{\mathrm{~mol} \%}$} & \multirow{2}{*}{$r_{1}{ }^{\mathrm{b}}$} & \multirow{2}{*}{$\frac{\eta_{\mathrm{sp}} / c^{\mathrm{c}}}{\mathrm{dl} \mathrm{g}^{-1}}$} & \multicolumn{2}{|c|}{ GPC } & \multirow{2}{*}{$\frac{T_{\mathrm{g}}}{{ }^{\circ} \mathrm{C}}$} \\
\hline & & & & & & & & & $\bar{M}_{w} \times 10^{-4}$ & $\bar{M}_{n} \times 10^{-4}$ & \\
\hline 1 & APAN2 & St & 0.58 & 20.5 & 6.3 & 1.4 & 0.41 & 0.40 & 4.75 & 2.24 & 98 \\
\hline 2 & & & 0.94 & 3.5 & 5.1 & 1.7 & 0.57 & 0.45 & 4.71 & 1.07 & 108 \\
\hline 3 & & & 2.29 & 17.0 & 6.7 & 3.9 & 0.51 & 0.59 & 7.42 & 1.16 & 132 \\
\hline 4 & & & 4.52 & 27.0 & 24.1 & 6.9 & 0.65 & 0.26 & 7.23 & 1.42 & 134 \\
\hline 5 & & & 14.71 & 27.0 & 39.6 & 17.6 & 0.75 & 0.65 & 3.31 & 1.76 & 140 \\
\hline 6 & & MMA & 1.19 & 3.0 & 10.5 & 1.2 & 0.59 & 0.93 & 11.59 & 1.59 & 129 \\
\hline 7 & & & 2.33 & 3.3 & 6.2 & 3.9 & 0.62 & 0.34 & 8.27 & 1.37 & 129 \\
\hline 8 & & & 2.45 & 3.2 & 10.6 & 5.1 & 0.47 & 0.48 & 6.49 & 1.03 & 131 \\
\hline 9 & & & 5.03 & 2.5 & 18.1 & 11.2 & 0.42 & 0.53 & 4.57 & 1.32 & 139 \\
\hline 10 & & & 17.75 & 3.5 & 14.5 & 20.1 & 0.75 & 0.50 & 2.81 & 0.56 & 145 \\
\hline 11 & APAN18 & $\mathrm{St}$ & 0.65 & 20.5 & 9.9 & 1.1 & 0.60 & 0.65 & 8.86 & 4.50 & 90 \\
\hline 12 & & & 3.78 & 17.0 & 12.8 & 4.2 & 0.88 & 0.61 & 9.23 & 4.19 & 72 \\
\hline 13 & & & 7.28 & 17.0 & 5.7 & 10.2 & 0.70 & 0.55 & 8.20 & 5.27 & 80 \\
\hline 14 & & MMA & 3.64 & 4.5 & 5.5 & 4.3 & 0.85 & 1.29 & 16.27 & 7.01 & 88 \\
\hline 15 & & & 7.02 & 4.5 & 7.7 & 9.3 & 0.73 & 1.47 & 9.89 & 3.49 & 92 \\
\hline 16 & & & 8.29 & 23.0 & 11.6 & 14.2 & 0.55 & 1.22 & 7.49 & 1.75 & 88 \\
\hline
\end{tabular}

a Polymerization conditions: $\left[\mathrm{M}_{1}\right]+\left[\mathrm{M}_{2}\right]=1-3 \mathrm{~mol}^{-1},[\mathrm{AIBN}]=2-7 \mathrm{mmol}^{-1}$ at $60^{\circ} \mathrm{C}$ in DMAc for APAN2 $\left(\bar{M}_{n}=3.3 \times 10^{3}\right)$, in benzene for APAN18 $\left(\bar{M}_{n}=4.2 \times 10^{3}\right)$.

b Monomer reactivity ratio, $\mathrm{d}\left[\mathrm{M}_{1}\right] / \mathrm{d}\left[\mathrm{M}_{2}\right]=r_{1}\left[\mathrm{M}_{1}\right] /\left[\mathrm{M}_{2}\right]\left(\left[\mathrm{M}_{1}\right] /\left[\mathrm{M}_{2}\right] \gg 1\right)$.

c $c=0.2 \mathrm{~g} \mathrm{dl}^{-1}$ at $30^{\circ} \mathrm{C}$ in DMAc $\left(\mathrm{M}_{2}=\mathrm{APAN} 2\right)$, in THF $\left(\mathrm{M}_{2}=\mathrm{APAN} 18\right)$.

molecular weight of the macromonomer. On the other hand, $r_{1}$ for the copolymerizations of APAN18 with St and MMA in benzene ( $0.60-0.88$ for $\mathrm{St}, 0.55-0.85$ for MMA) were higher than those for copolymerizations of AN18 with St and MMA in DMAc (0.32 for St, 0.46 for MMA). This would be due to the change in solvent because the monomer reactivity ratio of isopropenyltriazines depends on the solvent significantly as reported previously. ${ }^{16}$

The polymers containing triazine rings in the main-chain or side-chains show the poor solubility owing to the rigidity and the hydrogen bonding. The solubility of the resulting graft copolymers was better than that of random copolymers, although these polymers have different structure of segment. For example, poly(AN2-co-ST) was soluble in 1,4-dioxane, $m$-cresol, polar aprotic solvents, and strong acids, while the graft copolymer obtained from APAN2 with St was soluble in these solvents, THF, chloroform, and

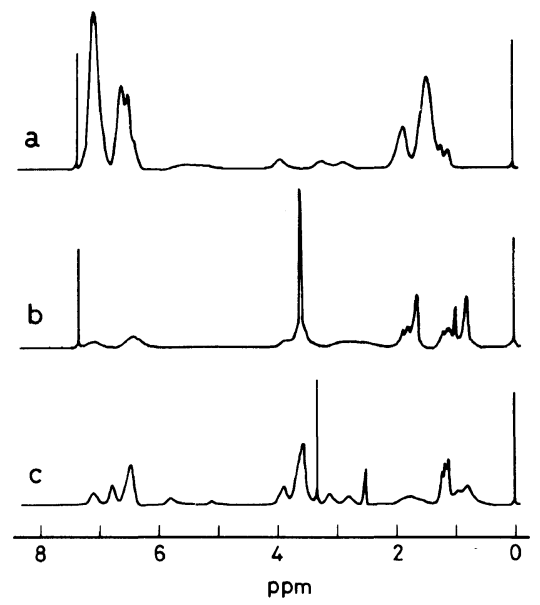

Figure 3. ${ }^{1} \mathrm{H}$ NMR spectra of (a) graft copolymer of APAN2 $\left(\mathrm{M}_{2}\right)$ with St $\left(\mathrm{M}_{1}\right)$ (run 1 in Table IV) in $\mathrm{CDCl}_{3}$, (b) graft copolymer of APAN2 with MMA (run 6) in $\mathrm{CDCl}_{3}$, and (c) graft copolymer of APAN2 with MMA (run 6) in DMSO- $d_{6}$.

pyridine.

${ }^{1} \mathrm{H}$ NMR spectra of the graft copolymers are shown in Figure 3. The spectra of the graft 
copolymers obtained from APAN2 with St and MMA, measured in $\mathrm{CDCl}_{3}$, show small broad signals based on the polyguanamine branches with relative sharp signals assigned to poly(St) or poly(MMA) backbone ( $a$ and $b$ in Figure 3). The signals of polyguanamine segment become sharp peaks and signals of the poly(MMA) segment become broad peaks in the spectrum measured in DMSO- $d_{6}$ (Figure $3, \mathrm{c})$. This may indicate that $\mathrm{CDCl}_{3}$ is a poor solvent for the polyguanamine, a good solvent for poly(St) and poly(MMA), whereas DMSO gives the reverse solubility. Similar behavior was observed in the graft copolymers of poly(MMA)-poly(dimethylethylammoniumethyl methacrylate $)^{17}$ and aromatic polyamide-poly(MMA). ${ }^{18}$

DSC measurement was carried out in order to estimate the miscibility of the branches and backbone in the graft copolymers. Only a single $T_{\mathrm{g}}$ was detected in the DSC thermograms for all the resulting graft copolymers as shown in Table IV. This would suggest that the branches and backbone are miscible. Figure 4 shows the relationships between $\cdot T_{\mathrm{g}}$ and composition for the graft copolymers of APAN2 and random copolymers of AN2. For

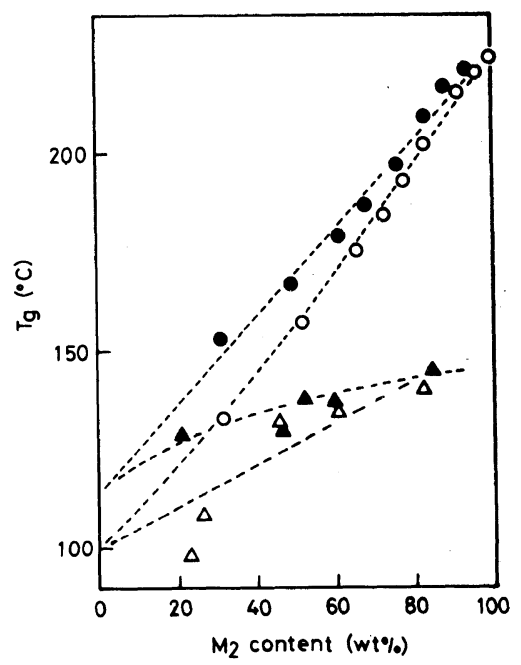

Figure 4. Relationships between $T_{\mathrm{g}}$ and $\mathrm{M}_{2}$ content in the copolymers. Copolymer types are: $(\mathrm{O})$, AN2-St; $(\mathbf{O})$, AN2-MMA; $(\triangle)$, APAN2-St; $(\boldsymbol{\Delta})$, APAN2-MMA. the random copolymers, $T_{\mathrm{g}} \mathrm{s}$ increased almost linearly with the content of AN2 and reached $T_{\mathrm{g}}$ of poly(AN2). $T_{\mathrm{g}}$ of graft copolymers was lower than that of random copolymers at the region of higher $\mathrm{M}_{2}$ content. The reason for this is that the $T_{\mathrm{g}}$ of APAN2 is lower than that of poly(AN2), although the molecular weight of APAN2 is not high enough to neglect dependence on $T_{\mathrm{g}}$.

DSC curves of the graft copolymers of APAN18 with St and MMA are shown in Figure 5 together with that of APAN18. Endothermic peaks on the heating processes and exothermic peaks on the cooling processes were observed at the temperature below the $T_{\mathrm{g}}$. On the basis of extensive studies on conventional comb-like polymers, ${ }^{19}$ the endothermic peaks should be ascribed to the melting of crystallized octadecyl side-chains, and exothermic peaks should be ascribed to their crystallization. Even if the octadecyl sidechains are attached to branches in the graft copolymer, they could be crystallized. The transition temperatures and heats of transition determined from the DSC curves are summarized in Table $\mathrm{V}$, which give the melting point on first heating process $T_{\mathrm{m} 1}$, crystallization

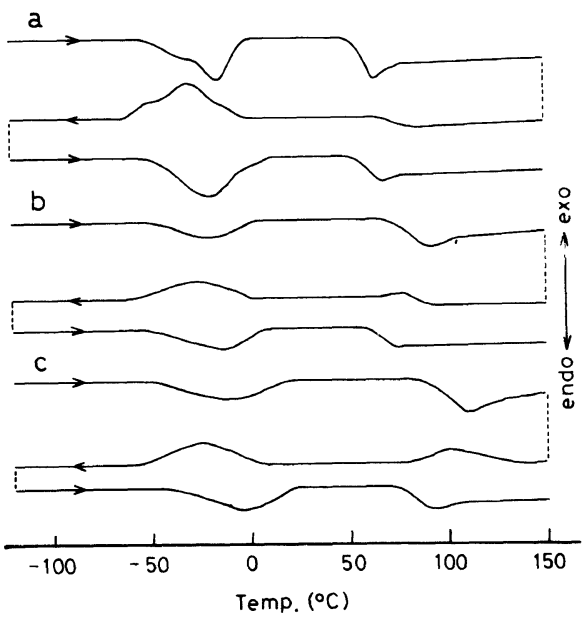

Figure 5. DSC curves of (a) APAN18, (b) graft copolymer of APAN18 $\left(\mathrm{M}_{2}\right)$ with St $\left(\mathrm{dm}_{2}=10.2 \mathrm{~mol} \%\right)$, and (c) graft copolymer of APAN18 with MMA $\left(\mathrm{dm}_{2}=9.3 \mathrm{~mol} \%\right)$ at the scanning rate of $10^{\circ} \mathrm{C} \mathrm{min}^{-1}$. 
Table V. Thermal properties of the graft copolymers

\begin{tabular}{|c|c|c|c|c|c|c|c|}
\hline \multirow{3}{*}{ Polymer } & \multirow{3}{*}{$\frac{\mathrm{M}_{2} \text { in copolymer }}{\mathrm{mol} \%}$} & \multicolumn{3}{|c|}{ Transition temperature } & \multicolumn{3}{|c|}{ Heat of transition } \\
\hline & & & ${ }^{\circ} \mathrm{C}$ & & \multicolumn{3}{|c|}{ kcal AN18 unit ${ }^{-1} \mathrm{~mol}^{-1}$} \\
\hline & & $T_{\mathrm{m} 1}$ & $T_{\mathrm{cr}}$ & $T_{\mathrm{m} 2}$ & $\Delta H_{\mathrm{m} 1}$ & $-\Delta H_{\mathrm{cr}}$ & $\Delta H_{\mathrm{m} 2}$ \\
\hline \multirow{2}{*}{ Poly(APAN18-co-St) } & 4.2 & - & - & - & - & - & - \\
\hline & 10.2 & -28 & -36 & -29 & 0.19 & 0.18 & 0.16 \\
\hline \multirow[t]{2}{*}{ Poly(APAN18-co-MMA) } & 4.3 & -31 & -33 & -4 & 0.30 & 0.32 & 0.32 \\
\hline & 9.3 & -19 & -36 & -20 & 0.33 & 0.27 & 0.27 \\
\hline Poly(AN18) & & -15 & -24 & -15 & 1.09 & 1.04 & 1.03 \\
\hline APAN18 & & -18 & -29 & -19 & 0.61 & 0.63 & 0.57 \\
\hline
\end{tabular}

Table VI. Thermal stability of the graft copolymers

\begin{tabular}{|c|c|c|c|}
\hline \multirow{3}{*}{ Polymer } & \multirow{3}{*}{$\frac{\begin{array}{c}\mathrm{M}_{2} \text { in } \\
\text { copolymer }\end{array}}{\mathrm{wt}^{\mathrm{m} \%}}$} & \multicolumn{2}{|c|}{$\begin{array}{l}\text { Weight loss } \\
\text { temperature }\end{array}$} \\
\hline & & \multirow{2}{*}{$\frac{5 \%}{{ }^{\circ} \mathrm{C}}$} & \multirow{2}{*}{$\frac{50 \%}{{ }^{\circ} \mathrm{C}}$} \\
\hline & & & \\
\hline \multirow[t]{4}{*}{ Poly(APAN2-co-St) } & 35.4 & 360 & 420 \\
\hline & 56.3 & 292 & 452 \\
\hline & 70.2 & 339 & 459 \\
\hline & 87.1 & 322 & 489 \\
\hline \multirow[t]{5}{*}{ Poly(APAN2-co-MMA) } & 28.6 & 296 & 254 \\
\hline & 57.3 & 343 & 518 \\
\hline & 63.9 & 293 & 454 \\
\hline & 80.6 & 291 & 496 \\
\hline & 89.2 & 295 & 516 \\
\hline \multirow[t]{2}{*}{ Poly(APAN18-co-St) } & 63.9 & 388 & 434 \\
\hline & 82.1 & 402 & 458 \\
\hline \multirow[t]{3}{*}{ Poly(APAN18-co-MMA) } & 65.4 & 304 & 432 \\
\hline & 81.2 & 323 & 456 \\
\hline & 87.4 & 309 & 476 \\
\hline Poly(AN2-co-St) & 77.9 & 344 & 525 \\
\hline Poly(AN2-co-MMA) & 65.4 & 298 & 459 \\
\hline
\end{tabular}

temperature $T_{\mathrm{cr}}$, melting point on second heating process $T_{\mathrm{m} 2}$, heat of fusion on first heating process $\Delta H_{\mathrm{m} 1}$, heat of crystallization $\Delta H_{\mathrm{cr}}$, and heat of fusion on second heating process $\Delta H_{\mathrm{m} 2}$. The heat of transition for APAN18 was lower than that for poly(AN18). This indicates that the degree of crystallinity would be lowered by the wide spacing between the side-chains in APAN18. The values further decreased for the graft copolymers. This would be due to the interfering effect of the backbone on access of the branches to each other.

The thermal stability of the graft copolymers was examined by TG-DTA. The results are summarized in Table VI. To investigate the influence of triazine rings in the branches of the graft copolymer on thermal stability, the Table includes the results of the random copolymers for comparison although the structure of a polyguanamine segment differs from that of a segment of random copolymer. The $5 \%$ and $50 \%$ weight loss temperatures of the graft copolymers were similar to that of random copolymers. These are relatively high temperatures for graft copolymers composed of the poly(St) or poly(MMA) segment as the backbone.

\section{REFERENCES}

1. P. F. Rempp and E. Franta, Adv. Polym. Sci., 58, 1 (1984).

2. R. Oda and Y. Morita, Kogyou Kagaku Zasshi, 64, 659 (1961).

3. Y. Yuki, H. Kunisada, and K. Tawara, Nippon Kagaku Kaishi, 74 (1987).

4. Y. Yuki, M. Ootani, K. Yukawa, and T. Akita, Kobunshi Ronbunshu, 35, 103 (1978).

5. H. Kunisada, Y. Yuki, S. Kondo, J. Miyatake, and C. Maeda, Polym. J., 22, 559 (1990).

6. T. Kelen and F. Tüdös, J. Macromol. Sci. Chem., A9, 1 (1975).

7. K. Sugiyama and S. Fukada, J. Polym. Sci., Polym. Lett. Ed., 22, 437 (1984).

8. Y. Yuki, H. Kunisada, J. Taniuchi, and N. Takizuka, Nippon Kagaku Kaishi, 224 (1987).

9. H. Kunisada, Y. Yuki, and S. Kondo, Macro- 
molecules, in press.

10. F. R. Mayo and F. M. Lewis, J. Am. Chem. Soc., 66, 1594 (1944).

11. J. Sierra-Vargas, E. Franta, and P. Rempp, Makromol. Chem., 182, 2603 (1981).

12. K. Ito, H. Tsuchida, A. Hayashi, T. Kitano, E. Yamada, and T. Matsumoto, Polym. J., 17, 827 (1985).

13. G. G. Cameron and M. S. Chisholm, Polymer, 26, 437 (1985).

14. G. G. Cameron and M. S. Chisholm, Polymer, 27, 1420 (1986).

15. Y. Tsukahara, N. Hayashi, X.-L. Jiang, and Y.
Yamashita, Polym. J., 21, 377 (1989).

16. H. Kunisada, Y. Yuki, S. Kondo, J. Miyatake, and C. Maeda, Polym. J., 22, 977 (1990).

17. Y. Chujo, T. Shinshino, Y. Tsukahara, and Y. Yamashita, Polym. J., 17, 133 (1985).

18. Y. Chujo, H. Kobayashi, and Y. Yamashita, Polym. J., 20, 407 (1988).

19. N. A. Platé and V. P. Shibaev, J. Polym. Sci., Macromol. Rev., 8, 117 (1974).

20. J. Brandrup and E. H. Immergut, "Polymer Handbook," 2nd ed, John Wiley \& Sons, New York, N.Y., 1975. 